\title{
Anaesthesia in a patient with subarachanoidal haemorrhage and high oxygen affinity haemoglobinopathy (HB york): case report
}

\author{
Enrico Monaca ${ }^{1 *}$, Tobias Jüttner ${ }^{1}$, Norbert Gattermann ${ }^{2}$ and Michael Winterhalter ${ }^{1}$
}

\begin{abstract}
Background: Approximately 90 haemoglobinopathies have been identified that result in abnormally high oxygen affinity. One of these is haemoglobinopathy York ( $\mathrm{HbY}$ ), first described in 1976. HbY causes an extreme leftward shift of the oxygen dissociation curve with the P50 value changing to $12.5-15.5 \mathrm{mmHg}$ (normal value $26.7 \mathrm{mmHg}$ ), indicating that approximately half of the haemoglobin is not available as oxygen carrier. Patients with haemoglobinopathies with increased oxygen affinity could suffer from the risk developing ischaemic complications due to a lack of functional oxygen carriers. This is, to best of our knowledge, the first case report on a patient with $\mathrm{HbY}$ published in connection with anesthesia.
\end{abstract}

Case Presentation: A 42-year-old female with a severe headache and Glasgow coma scale (GCS) of 15 was admitted to the neurosurgical intensive care unit with a ruptured, right sided ICA aneurysm with consecutive subarachnoid haemorrhage [Fisher III, World Federation of Neurosurgical Societies (WFNS) I)]. The medical history of the patient included an erythrocytosis $(\mathrm{Hb} 17.5 \mathrm{~g} / \mathrm{dl}$ ) on the base of a high-oxygen-affinity haemoglobinopathy, called $\mathrm{Hb}$ York ( $\mathrm{HbY}$ ). With no time available to take special preoperative precautions, rapid blood loss occurred during the first attempt to clip the aneurysm. General transfusion procedures, according to the guidelines based on haemoglobin and haematocrit values, could not be applied due to the uncertainty in the oxygen carrier reduction. To maintain tissue oxygen supply, clinical indicators of ischaemia were instead utilized to gauge the appropriate required blood products, crystalloids and colloids replacements. Despite this, the patient survived the neurosurgical intervention without any neurological deficit.

Conclusions: Family members of patients with HbY (and other haemoglobinopathies with increased oxygen affinity) should undergo clinical assessment, particularly if they are polycythaemic. If the diagnosis of $\mathrm{HbY}$ is confirmed, they should carry an "emergency anaesthesiology card" in order to avert perioperative risks arising from their "hidden" anemia.

Keywords: Haemoglobinopathy, Hb York, Oxygen affinity, Neuroanaesthesia, Subarachnoid haemorrhage, Anaemia, Hypoxia

\section{Background}

Haemoglobinopathy is defined as a genetic defect that results in an abnormal structure of one of the globin chains of the haemoglobin molecule. It is the most frequently occurring monogenic disorder [1]. To date, more than 1000 varieties have been described. Although haemoglobinopathies often entail abnormal laboratory

\footnotetext{
* Correspondence: enricomonaca@med.uni-duesseldorf.de

${ }^{1}$ Department of Anaesthesiology, Heinrich-Heine-University, Moorenstrasse 5D-40225, Düsseldorf, Germany

Full list of author information is available at the end of the article
}

findings like erythrocytosis and/or haemolysis, only a few cause severe clinical symptoms. Well-known examples of haemoglobinopathies with severe clinical phenotype are sickle cell disease, beta-thalassemia or $\mathrm{Hb} \mathrm{S/C}$ disease.

Approximately 90 haemoglobinopathies have been identified that result in abnormally high oxygen affinities. The first was reported in 1966 on an 81-year-old patient who presented with polycythemia [2]. Decreased oxygen supply causes erythrocytosis, with clinical features depending on the degree of abnormal oxygen 
affinity. This subgroup of haemoglobinopathies includes haemoglobinopathy York (HbY), first described in 1976 [3]. A second and third case was reported in 1983 and 2001, respectively $[4,5]$. Patients with haemoglobinopathies with increased oxygen affinity could suffer from an additional increased risk developing ischaemic complications when undergoing surgery with a higher risk of blood loss or circulatory arrest due to a lack of functional oxygen carriers. In 1997, an 11-year-old patient with $\mathrm{Hb}$ Bryn Mawr was reported who was intensively prepared for a cholecystectomy by performing partial exchange transfusion to prevent tissue hypoxia during anaesthesia. $\mathrm{Hb}$ Bryn Mawr is an unstable $\mathrm{Hb}$ variant resulting in congenital haemolytic anaemia and increased oxygen affinity [6]. We wish to report the case of a patient with $\mathrm{HbY}$ who survived a life-threatening situation characterized by subarachnoid haemorrhage and severe perioperative aneurysmal bleeding. To the best of our knowledge, this is only the fourth published case of $\mathrm{HbY}$ worldwide and the first case published in connection with anaesthesia.

\section{Case presentation}

A 42-year-old female with a severe headache and Glasgow Coma Scale (GCS) of 15 was admitted from a regional hospital close to our neurosurgical intensive care unit. Digital subtraction angiography showed a ruptured, right-sided ICA aneurysm near the bifurcation followed by a subarachnoid haemorrhage (Fisher III, World Federation of Neurosurgical Societies I: GCS 15, no motoric deficit). A neurological examination revealed no deficits. The medical history of the patient included obesity (a body mass index of 29), Hashimoto thyroiditis, and an erythrocytosis $(\mathrm{Hb} 17.5 \mathrm{~g} / \mathrm{dl})$, in addition to the $\mathrm{HbY}$. The diagnosis of $\mathrm{HbY}$ was initially performed at the University of Ulm (Germany) in 2002 through molecular genetic analysis, subsequent to the exclusion of alternative explanations for erythrocytosis. Preoperative laboratory findings showed a haematocrit of $54 \%, \mathrm{Hb} 17.5 \mathrm{~g} / \mathrm{dl}$, reticulocytes $25 / 1000$ and erythrocytes $6.2 \times 10^{6} / \mu \mathrm{l}$.

After induction of anaesthesia with propofol $(2 \mathrm{mg} /$ $\mathrm{kg})$, remifentanyl $(0.5 \mu \mathrm{g} / \mathrm{kg} / \mathrm{min})$ and rocuronium $(70 \mathrm{mg})$, an arterial and a central-venous catheter were placed in addition to two peripheral intravenous $17 \mathrm{G}$ catheters. The lungs were ventilated with a fraction of inspired oxygen $\left(\mathrm{FiO}_{2}\right)$ of 0.5 and a minute ventilation $(\mathrm{MV})$ of $110 \mathrm{ml} / \mathrm{min} / \mathrm{kg}$. Nimodipine was continually administered at a rate of $1 \mathrm{mg} / \mathrm{h}$. Anaesthesia was maintained with Propofol $(8 \mathrm{mg} / \mathrm{kg} / \mathrm{h})$ and Remifentanyl $(0.25 \mu \mathrm{g} / \mathrm{kg} / \mathrm{h})$. The operation was started and progressed uneventfully until the surgeon tried to dissect the basis of the aneurysm, which led to severe bleeding. Several temporary clips were required to stop the haemorrhage (approx. $1600 \mathrm{ml}$ ). Subsequent to volume resuscitation with $1000 \mathrm{ml}$ Ringer's solution and $500 \mathrm{ml}$ of volume expander (hydroxyethyl starch; HAES) 130/ 0.4 , the haemoglobin value was $10.8 \mathrm{~g} / \mathrm{dl}$. During the bleeding interval, no $\mathrm{S}-\mathrm{T}$ segment changes were observed. However, typical signs of rapid fluid loss, such as a moderately increased heart rate and a temporary drop in blood pressure, were present. Systolic blood pressure was always kept between $120 \mathrm{mmHg}$ and $140 \mathrm{mmHg}$ using noradrenalin in varying dosages (max. $0.25 \mu \mathrm{g} / \mathrm{kg} / \mathrm{min}$ ). Meanwhile, the patient received 6 units of packed red blood cells (PRBC) and further fluid substitutions.

Further bleeding was stopped by continuous compression with $\mathrm{TachoSil}^{\circledR}$, enabling the obliteration of the aneurysm. No vascular occlusions were detected on an indocyanine green angiography. The blood pressure was subsequently pharmacologically raised to a systolic value of approximately $140 \mathrm{mmHg}$, with no further detectable haemorrhaging. It was possible to extubate the patient within a few minutes upon completion of the operation. Immediate neurological assessment revealed no detectable deficits. The patient was transferred to the intensive care unit with haemoglobin of $16.8 \mathrm{~g} / \mathrm{dl}$. Further recovery was uneventful.

\section{Conclusions}

This case report describes a high urgency neurosurgical intervention in a patient with HbY. There was no time for taking special preoperative precautions, as described by Larson et al. [6], as our patient experienced sudden and rapid blood loss. The first $\mathrm{Hb}$ value was $10.8 \mathrm{~g} / \mathrm{dl}$. The guidelines of the German Medical Association recommend that attempts should be made to maintain intraoperative $\mathrm{Hb}$ concentrations above $10 \mathrm{~g} / \mathrm{dl}$ in case of acute bleeding. Taking into account the fact that approximately half of the patient's haemoglobin was nonfunctional, a more accurate estimate of the "functional" or "actual" Hb level would have been about $5.4 \mathrm{~g} / \mathrm{dl}$. Fortunately, the reaction to the sudden blood loss was not dramatic. There was neither clinical nor laboratory evidence of ischemia. Our patient was generously transfused, achieving a haemoglobin concentration of $16.8 \mathrm{~g} /$ $\mathrm{dl}$ by the end of surgery. However, it appears rather difficult to assess how much haemoglobin was functional when a blood loss of $1600 \mathrm{ml}$ (containing approximately $800 \mathrm{ml} \mathrm{HbY}$ ) was substituted with $1200 \mathrm{ml}$ "healthy" PRBC with a haematocrit of $60 \%$. When performing such a rough or 'ballpark' estimate, the use of the following calculation is proposed: Starting with a $\mathrm{Hb}$ of $17.5 \mathrm{~g} /$ $\mathrm{dl}$, a blood loss of approximately $40 \%$ to $10.8 \mathrm{~g} / \mathrm{dl}$ was nearly compensated with PRBC to $\mathrm{Hb} 16.8 \mathrm{~g} / \mathrm{dl}$. The lost blood contained $\mathrm{HbY}$ and "healthy" blood in an equal ratio, thus $20 \%$ of lost blood was "pure" HbY. This was substituted with $100 \%$ healthy blood, leading to a shift in 
the HbY:"healthy" blood ratio of 30:70 (50\%-20\%/ $50 \%+20 \%)$ and an estimated value of a functional haemoglobin concentration of $11.8 \mathrm{~g} / \mathrm{dl}$ (70\% of $16.8 \mathrm{~g} / \mathrm{dl})$. However, a storage-related depletion of 2.3-diphosphoglycerate (2.3-DPG) content in erythrocytes causing an additional leftward shift of the oxygen-dissociation curve could decrease oxygen transport capacity.

During anaesthesia, we discover no deviation in pulse oxymetry readings in comparison to arterial blood gas analysis. This fact stands in apparent contrast to a theoretical overestimation of pulse oxymetric values, as half of the haemoglobin is already- and remains irreversible saturated with oxygen. For example, overestimated values measured with commonly used two-wave pulse oxymeters are found in patients with carbon monoxide intoxication due to the similar absorption spectrum of irreversible saturated haemoglobin and oxygenated haemoglobin. In addition overestimated oxymetry readings have also been found in, for example, high oxygen affinity haemoglobin Koln, which is associated with a leftshifted oxygen dissociation curve [7]. Taking into account the limitations of conventional oximetry, especially in these patient populations, an alternative monitoring method should be employed, such as arterial blood gas analysis or end-tidal oxygen concentration monitoring $[8,9]$. Furthermore, new presence of arrhythmia or changes of S-T segment, an increase of oxygen extraction rate greater than $50 \%$ and a decrease of oxygen consumption of more than $10 \%$ could serve as commonly accepted assessment of an adequate oxygen delivery.

The overall goal was to maintain blood pressure at a preoperative level until the aneurysm was taken care of. This was achieved by adjusting accordingly the levels of noradrenalin administration. During the acute bleeding, the preferred technique for gaining control over the ruptured aneurysm was to temporarily occlude the vessel instead of a transiently decreasing the mean arterial pressure. As part of the triple- $\mathrm{H}$ therapeutic strategy, haemodilution could not be performed as the team identified hypoxia as the most dangerous threat to the patient and tried to stabilize the "actual" $\mathrm{Hb}$ at a reasonably high level. The choice of anaesthetic drugs led to a rapid and smooth emergence from anaesthesia, which allowed an early neurological assessment.

The patient's history of haemoglobinopathy begun when a general practitioner suspected polycythaemia vera as an underlying cause for a chronic erythrocytosis. Common causes, including cigarette smoking, psychosocial stress, chronic residence at high altitudes and chronic lung disease, were excluded. Finally, $\mathrm{HbY}\left(\alpha_{2} \beta_{2}^{146 \text { Pro }}\right)$ was identified by DNA sequencing, which indicated an autosomal dominant inherited point mutation of codon 146, where adenosine was exchanged for cytosine ( $\mathrm{CAC} \Rightarrow \mathrm{CCC}$ ). The mutation causes a change from histidine to proline at position 146 in the $\beta$-globin chain. The mutant globin has approximately twice the normal affinity for oxygen [3], causing an extreme leftward shift of the oxygen dissociation curve, with the P50 changing from $26.5 \pm 1.0 \mathrm{mmHg}$ to approximately $12.5-15.5 \mathrm{mmHg}[4,5,10]$. To date, only heterozygotes carriers have been detected, suggesting that this mutation is lethal for homozygotes. In heterozygote individuals the red blood cells contain a 1:1 mixture of $\mathrm{HbY}$ and normal HbA. The mutant HbY always remains saturated with $\mathrm{O}_{2}$ and thus cannot serve the physiological function of oxygen delivery. As a consequence of decreased tissue oxygen supply, erythropoietin production in the kidneys is upregulated, resulting in erythrocytosis. Preoperative laboratory findings confirmed an usual compensatory mechanism for chronic but moderate tissue hypoxia.

Young individuals with $\mathrm{Hb}$ York are usually asymptomatic. However, they are permanently at risk to suffer from a state of "functional anaemia". Therefore, the following general advice may be justified: insufficient tissue perfusion should be avoided by generous fluid intake, especially during hot weather or when pyrexia or diarrhoea occurs; all pulmonary infections should be treated without delay; and patients should not smoke and should avoid travelling to high-altitude locations. Until more knowledge has accumulated, it is difficult to comment on the prognosis of individuals with $\mathrm{HbY}$. As yet, these individuals seem to have a normal life expectancy. Nevertheless, they may become symptomatic when their ability to compensate for their 50\% dysfunctional haemoglobin is compromised by congestive heart failure, coronary heart disease, cerebrovascular insufficiency, peripheral arterial disease, chronic or acute lung disease, or pregnancy. In addition, carbon monoxide intoxication or intoxications causing methaemoglobinemia or sulfhaemoglobinemia may lead to critical situations due to a critical level of dysfunctional haemoglobin. The same may be true for rapid blood loss.

Chronic compensatory changes in patients suffering from quantitative and qualitative anaemic diseases, include an up regulated cardiac output, a decreased vascular resistance, increased amount of erythrocyte and a higher content of 2.3-DPG, which causes a right-shift and thus a minimal compensation of the extremely left shifted oxygen dissociation curve. Erythrocytosis causing increased blood viscosity can lead to thromboembolic complications, especially in elderly individuals with haemoglobinopathy [11]. Recent investigations suggest that preoperative anaemia increases the risk of postoperative mortality [12]. In our patient, the preoperative situation was characterized by a "functional" anaemia, a lack of an appropriate level of oxygen carriers, despite a $\mathrm{Hb}$ concentration of $17.5 \mathrm{~g} / \mathrm{dl}$. Severe intraoperative haemorrhaging aggravated the situation. Fortunately, the 
patient tolerated this complication rather well with the immediate volume substitution, catecholamine administration and a generous blood transfusion. We feel that our experience does not allow us to draw any conclusions as to the benefit of partial exchange transfusions as a preoperative preparatory regimen. Additionally, the special precautions carried out by Larson et al. in 1997 in a patient with $\mathrm{Hb}$ Bryn Mawr seemed to be an excessive precaution [6]. From our point of view, a young person who lived his entire life in complete stability and most probably in adequate oxygen delivery environment does not need an exchange transfusion for a minor procedure.

Family members of patients with $\mathrm{HbY}$ (and other haemoglobinopathies with increased oxygen affinity) should undergo clinical assessment, particularly if they are polycythaemic. If the diagnosis of $\mathrm{HbY}$ is confirmed, they should carry an "emergency anaesthesiology card" in order to avert perioperative risks arising from their "hidden" anaemia. It should be emphasized that general transfusion guidelines are not applicable to individuals with this rare condition. Therapeutic attempts at decreasing the abnormal oxygen affinity using bezafibrates are still being investigated. Venesection seems to only be sensible in case of repetitive thrombotic events, but the risk of an ischaemia is always present in these patients.

\section{Consent}

Written informed consent was obtained from the patient for publication of this case report. A copy of the written consent is available for review by the Editor-in-Chief of this journal.

\section{Competing Interests}

The authors declare that they have no competing interests.

\section{Authors' contributions}

EM: Preparation of the manuscript and involvement in the case. $\mathrm{TJ}$ : Anaesthesiologist involved in the case. NG: Substantial hematological background and preparation of the manuscript. MW: Preparation of the manuscript. All authors read and approved the final manuscript.

\section{Author details}

${ }^{1}$ Department of Anaesthesiology, Heinrich-Heine-University, Moorenstrasse 5D-40225, Düsseldorf, Germany. ${ }^{2}$ Department Of Haematology, Oncology and Clinical Immunology, Heinrich-Heine-University, Moorenstrasse 5, D-40225, Düsseldorf, Germany.

Received: 12 October 2011 Accepted: 27 July 2012

Published: 8 August 2012

\section{References}

1. Flint J, Harding RM, Boyce AJ, Clegg JB: The population genetics of the haemoglobinopathies. Bailliere Clin Haematol 1998, 11(1):1-51.

2. Charache S, Weatherall DJ, Clegg JB: Polycythemia associated with a hemoglobinopathy. J Clin Invest 1966, 45(6):813-822

3. Bare GH, Bromberg PA, Alben JO, Brimhall B, Jones RT, Mintz S, Rother I: Altered C-terminal salt bridges in haemoglobin York cause high oxygen affinity. Nature 1976, 259(5539):155-156.
4. Kosugi H, Weinstein AS, Kikugawa K, Asakura T, Schroeder WA: Characterization and properties of $\mathrm{Hb}$ York (beta $146 \mathrm{His}$ leads to Pro). Hemoglobin 1983, 7(3):205-226.

5. Misgeld E, Gattermann N, Wehmeier A, Weiland C, Peters U, Kohne E: Hemoglobinopathy York [beta146 (HC3) His==> Pro]: first report of a family history. Ann Hematol 2001, 80(6):365-367.

6. Larson PJ, Friedman DF, Reilly MP, Kattamis AC, Asakura T, Fortina P, Cohen AR, Kim HC, Manno CS: The presurgical management with erythrocytapheresis of a patient with a high-oxygen-affinity, unstable $\mathrm{Hb}$ variant (Hb Bryn Mawr). Transfusion 1997, 37(7):703-707.

7. Gottschalk A, Silverberg M: An unexpected finding with pulse oximetry in a patient with hemoglobin Koln. Anesthesiology 1994, 80(2):474-476.

8. Kuji A, Satoh Y, Kikuchi K, Satoh K, Joh S: The anesthetic management of a patient with hemoglobin M(Iwate). Anesth Analg 2001, 93(5):1192-1193. table of contents.

9. Firth PG: Anesthesia and hemoglobinopathies. Anesthesiol Clin 2009, 27 (2):321-336.

10. Siggaard-Andersen O, Wimberley PD, Fogh-Andersen N, Gothgen $\Vdash$ : Arterial oxygen status determined with routine $\mathrm{pH} / \mathrm{blood}$ gas equipment and multi-wavelength hemoximetry: reference values, precision, and accuracy. Scand J Clin Lab Invest Supp/ 1990, 203:57-66.

11. Dash S, Das R: Late emergence of polycythemia in a case of $\mathrm{Hb}$ Chandigarh [beta94(FG1)Asp-> Gly]. Hemoglobin 2004, 28(3):273-274.

12. Beattie WS, Karkouti K, Wijeysundera DN, Tait G: Risk associated with preoperative anemia in noncardiac surgery: a single-center cohort study. Anesthesiology 2009, 110(3):574-581.

doi:10.1186/1471-2253-12-19

Cite this article as: Monaca et al:: Anaesthesia in a patient with subarachanoidal haemorrhage and high oxygen affinity haemoglobinopathy (HB york): case report. BMC Anesthesiology 2012 $12: 19$.

\section{Submit your next manuscript to BioMed Central and take full advantage of:}

- Convenient online submission

- Thorough peer review

- No space constraints or color figure charges

- Immediate publication on acceptance

- Inclusion in PubMed, CAS, Scopus and Google Scholar

- Research which is freely available for redistribution 